\title{
Determinants of Service Quality in High-end IT Enabled Services: An Indian Perspective
}

\author{
*Vandana Srivastava1, Subhash Datta², A.Sharfuddin³, Sanjeev Kishore ${ }^{4}$ \\ ${ }^{1}$ IILM Institute for Higher Education, New Delhi, India \\ 2Institute of Management Technology, Nagpur, India \\ ${ }^{3}$ Jamia Millia Islamia (A Central University), New Delhi, India \\ ${ }^{4}$ Indian Railways, India \\ *srivastava.vandana@gmail.com
}

\begin{abstract}
IT enabled Services (ITeS) have charted tremendous growth in India over the last two decades. Over the years, the service domain has evolved to include high-end services as well as traditional services. Along with fresh opportunities, the evolving service landscape brings new challenges for the service providers, with quality being the prime challenge. As the nature of services change, new determinants of service quality emerge. Towards this aim, this research paper presents a fresh perspective of determinants of service quality in high-end ITeS by integrating elements from traditional service quality models and frameworks with issues related to technology and organizational relationship management. The research involves a two-phase study. Findings from the literature survey and a qualitative study are used to identify the determinants of service quality and to create a hypothetical model. Based on data collected from senior executives of Indian service providers, the second phase of the study presents a regression model of the determinants. The combined linear effects of the determinants were found to account for $76.8 \%$ of the variation in success of high-end ITeS projects. The regression model highlights the critical and significant role played by Knowledge Management, Technology Management and Service Design and Delivery in service quality. The findings further highlight the potential of mechanisms for capturing and re-using organizational learning in reducing service quality gaps. The strategic implications presented in the paper will provide a starting point for service providers aiming to engage in providing high-end IT-enabled Services.
\end{abstract}

Keywords: ITeS, service quality, high-end services, India, determinants, knowledge management

\section{Introduction}

In the rapidly changing external environment, organizations need diverse and high-quality services to survive and excel. They often look beyond their boundaries to form outsourcing (eSourcing) relationships with other organizations. Services provided remotely using internet and the global telecommunications infrastructure, are known as IT enabled Services (ITeS) (Hyder, Heston and Paulk, 2004). These services range from routine to strategic and cover tasks that may be critical or otherwise. One of the most well known forms of ITeS is outsourcing. India is outsourcing history dates back to the 1980s, however, it was the mid 1990s that saw the emergence of India as the outsourcing hub. Termed as India's sunshine sector, the ITeS sector has continued to chart double-digit growth. With the compounded annual growth rate of over $24 \%$ in the last decade, the Indian IT/ITeS industry has emerged as a key growth engine for the economy, contributing around 5.6\% to the country's gross domestic product in financial year 2010 and providing direct employment to about 2.3 million people (CRISIL Report, 2011). One of the main reasons for the strong credentials of Indian service providers is good service quality with adherence to global standards. Indian service providers have used globally accepted quality frameworks such as ISO 9001:2000, COBIT, COPC, TQM, BS 15000 or eSCM. Each of these frameworks is designed for different specific service domains (Hyder et al, 2004). While India is well established as the global outsourcing hub, it faces challenges from other countries. Countries such as Philippines and China are fast catching up (CII Report on ICT and Emerging Technologies, February 2011). Moreover, a perceptible shift in the nature of services being outsourced has been observed. In the last three or four years the nature of services provided by Indian service providers has extended to include high-end complex tasks (NASSCOM and Booze \& Co. Report, 2010). Experience has shown that the companies providing services also undergo a process of evolution through learning. As they master low-end services, there is invariably a strategic impulse to enter into high-end services, which provide greater margins and 
more long lasting relationships. Indian service providers that once specialized in basic work have started providing high value services such as research and design, business transformation services, high-end design and engineering solutions across diverse industry verticals (NASSCOM and Booze \& Co. Report, 2010). Most of the quality frameworks used in traditional ITeS have evolved in a grounded manner to specific context. While the process of evolution has ensured that, they are valid and reliable in the specific contexts, their applicability to slightly varying contexts remains doubtful. In a dynamic environment, as the nature of services changes, there is a need to keep revisiting these frameworks as new determinants of service quality emerge rendering these frameworks ineffective. The determinants of service quality evolve, undergo change and have to be validated and re-validated iteratively, as time passes. Thus, it was imperative to identify factors that affect service quality in high-end ITeS. With this aim, the paper begins with a review of the literature. Various studies on service quality have proposed different determinants of service quality specific to the context. A review of this literature, in view of the challenges faced by ITeS service providers, is presented to give an understanding of the key determinants of service quality in high-end ITeS. The next section discusses the methodology used in the research. The results of the investigations into the factors are analyzed and the findings are reported. Conclusion, including implications for future research and practice in this area, are presented finally.

\section{Literature Review}

Background studies have shown that between $20 \%$ and $25 \%$ of outsourcing relationships fail in the first 2-3 year and more than $50 \%$ fail within 5 years. In $70 \%$ of the cases the inability of the service provider to understand the clients' requirements, high costs and poor service quality have been cited as the most common challenges (Hyder et al, 2004; Ren and Zhou, 2008). According to Ramachandran and Voleti (2004), the two capabilities critical for success in the IT space are the capabilities to understand customer needs in specific domains and acquiring business, and capabilities to execute them efficiently. This clearly calls for a more organization-wide, pervasive and process-oriented approach to quality management. With this perspective, the literature on service quality in different service types was reviewed. One of the most widely used service quality models; the Gaps model (Parasuraman, Zeithaml and Berry, 1985) defines Tangibles, Reliability, Responsiveness, Assurance and Empathy as the dimensions, which represent the core criteria that customers' employ in evaluating service quality. However, different researchers have questioned their applicability in different service domains. While some studies have extended the SERVQUAL dimensions, others have re-interpreted them. Drawing from the literature on quality management in ITeS and the variants of the SERVQUAL dimensions, the following determinants of service quality were identified:

Knowledge Management: Hyder et al (2004) have identified Knowledge Management as critical to outsourcing. They have defined Knowledge Management as managing organizational information and knowledge so that personnel have easy access to the knowledge needed to electively perform their work. As ITeS move from routine to more knowledge intensive tasks, effective knowledge management is desirable for ensuring quality of service (Ramani, 2000; Susarla, Barua and Whinston, 2003; Willcocks, Hindle, Feeny and Lacity, 2004; Aron, Bandopadhyay, Jayanty and Pathak, 2008). In context of IS systems, Yoon and Suh (2004) have added two more dimensions, namely, "process" and "education" to the SERVQUAL dimensions. These refer to institutionalization of processes for capture and dissemination of task related knowledge. On similar lines, Sureshchandar, Rajendran and Anantharaman (2002) have also proposed systematization processes as a dimension of service quality.

People Management: Non-availability of trained staff and management of offshore teams directly affects service quality (Lacity and Willcocks, 1998; Beaumont and Costa, 2002). Understanding and fulfilling organizational needs for personnel and skills, encouraging appropriate behaviors to effectively deliver service, and effective management of cross cultural issues between organizations have been found to result in successful outsourcing relationships (Hyder et al, 2004; Thelen, Zarb, Honeycutt Jr. and Murphy, 2010). People management maps to SERVQUAL dimensions of "empathy". "Empathy", redefined in terms of competence of staff, team support, feedback and participation (Mukherjee and Malhotra, 2006; Ganguli and Roy, 2010) and horizontal communications (Zeithaml, Parasuraman and Berry, 1990; Ronnback, Witell and Enquist, 2009) has been identified as a critical factor for service quality. 
Performance Evaluation: It is important for both clients and service providers to monitor the quality of service by tracking efforts in real time (Aron et al, 2008; Harmon, Hensel and Lukes, 2006). Quality management involves micro-management by service providers, thereby requiring that the service provider for monitoring performance (Rottman \& Lacity, 2006) employ a variety of metrics. Parasuraman et al (1985) have also emphasized on the importance of appropriate measurement systems. Jiang, Klein and Carr (2002) who have emphasized on the need to align quality goals and expectations prior to initiating any project and continuing to evaluate them for successful outsourcing relationships have also presented this view. Hyder et al (2004) have also posited that effective quality management depends on capture and analysis of metrics defining the organization's performance.

Service Design and Delivery In context of ITeS, the original SERVQUAL dimensions of "Reliability", "Responsiveness" and "Assurance" have either been modified or re-interpreted by several studies to emphasize service design and delivery. Efficiency, fulfillment, system availability, responsiveness, and contact (Zeithaml, Parasuraman and Malhotra, 2002; Parasuraman, 2005), ease of use, website content and functionality (Sohn and Tadisina, 2008; Alzola and Robaina, 2005) have been proposed as service quality dimensions by different researchers. Reliability and responsiveness have been identified as critical dimensions by Blanchard and Galloway (1994), Yoon and Suh (2004), Hsieh, Lin and Chen (2007) and Sohn and Tadisina (2008). Infact, Blanchard and Galloway (1994) have proposed that reliability should be treated as a pre-requisite to all other dimensions. It is also very important for the service provider to know that the right service has been produced and that it has been produced correctly (Blanchard and Galloway 1994; Sureshchandar et al, 2002. This view is also shared by Hyder et al (2004) and Duraivelu and Suryaprakasa (2006) who have emphasized on the need to translate the client's requirements into a detailed design of how it will be provided, and on effectively deploying that design across the entire life-cycle.

Technology Management: Since ITeS involves sharing and transfer of data, issues regarding loss of data and information security are very real and tangible (Beaumont and Costa 2002; Ren and Zhou, 2008). Hyder et al (2004) have posited that managing availability and adequacy of the technology infrastructure used to support the delivery of the services, controlling the existing technology, managing changes to technology, and maintaining technology availability, reliability, accessibility, and security are critical. This view can also be found across various studies on SERVQUAL in different service contexts. Privacy (Zeithaml, Parasuraman and Malhotra, 2002; Parasuraman, 2005) and assurance of electronic service recovery (Parasuraman, 2005) have been proposed as service quality dimensions by different researcher. Zeithaml et al (2002), Alzola and Robaina (2005), Sohn, and Tadisina (2008) have proposed that Security and Privacy are extremely critical in such contexts and should be treated as a separate dimension instead of being clubbed as a part of "Assurance". Based on their study of hybrid services, which are a combination of human-human and humantechnology interactions, Ganguli and Roy (2010) have also identified technology security as an additional dimension. Identification, mapping and management of technology to make the service seamless have been defined as critical for service quality by Sureshchandar et al (2002), Ganguli, and Roy (2010).

Rationale and Objectives: The global demand for high-end ITeS is still in initial phases and has tremendous potential for Indian service providers. Hence, it requires extensive research. The service quality frameworks used by service providers in traditional services use dimensions or metrics, which may not be applicable in complex, service domains. In addition, often organizations do not adopt such frameworks; instead, they devise their own indigenous quality management systems specific to their context. An understanding of the determinants in these contexts, therefore, paves the way for better quality management. Thus, there emerged a need to conduct a research to identify the factors that affect service quality in context of ITeS. Moreover, there was also a lack of focused research on high-end and complex ITeS in India. In order to address these issues we have tried to integrate the elements from traditional service quality instruments such as the SERVQUAL with the capability areas of eSourcing Capability Maturity Model (eSCM) (Hyder et al, 2004) to develop scales in order to identify and measure the factors influencing service quality and project success in high-end ITeS. The findings of the study would be useful in investigating the interrelation between the various factors and service quality. The findings will be extremely useful for new entrants and niche' service providers aiming to engage in providing high-end services. Hence the objectives of this study were:

- To determine the factors influencing service quality in Indian ITeS in context of high-end services, 
and,

- To establish a relationship between the various factors.

\section{Methodology}

The study was carried out in 2010 and 2011 in the New Delhi- National Capital Region (NCR), which is one of the major outsourcing hubs of India. The research was a primary research carried out in two phases. Phase I or the exploratory phase, was carried out as a qualitative research and was aimed at defining the tentative constructs. The Phase II or the Descriptive phase of the research was carried out as a quantitative research aimed at identifying the factors and their inter-relationships. In the present study, quantitative research was preceded by a qualitative research phase because qualitative methodology is a valuable approach to identify or hypothesize important variables related to new concept for understanding and developing the phenomenon.

Phase I: the Exploratory Phase: The Exploratory phase aimed at defining the tentative constructs. This was carried out using personal interviews followed by semi-structured questionnaires as they provide a broad view of behaviors (Scandura and Williams, 2000). Managers from three organizations, which provided highend services, were interviewed. All were located in the New Delhi-NCR region. The interviewees were senior officers such as Vice President (Quality) and Country Head. The interviews were open-ended and were aimed at getting an understanding of the actual quality management practices across different organizations and the associated challenges. Using the findings of the study, the next step was to carry out more structured question-based surveys from internal stakeholders of service provider organizations. The questions were developed on the lines of SERVQUAL instrument and capability areas of the eSCM. Since both managers and front-line employees have an important role in service quality (Parasuraman et al, 1985), the surveys were administered to both front-line employees and managers. Two separate sets of questions were prepared for the front-line employees and the senior level managers. The surveys included questions on role of teamwork, employee - job fit, technology-job fit, perceived control, horizontal communication, propensity of the marketing team to overpromise, management commitment to service quality, processes and management of technology. Using the surveys, qualitative responses were collected from 5 service level employees and managers each from 5 different organizations. The demographic profile of the respondents was selected to ensure that respondents with at least 5 years of experience were chosen. Discussions of similar, recurrent and important themes were drawn together and compared with the overall framework identified at the time of extensive literature review. The following variables were identified as factors that affect service quality in high-end IT enabled Services: Knowledge Management, People Management, Performance Evaluation, Service Design and Delivery, and Technology Management. The determinants, thus identified, and their relationship with service quality and hence project success, are represented in Figure 1 as a hypothetical model.

Figure 1: Hypothetical model representing the Relationship between Determinants and Service Quality

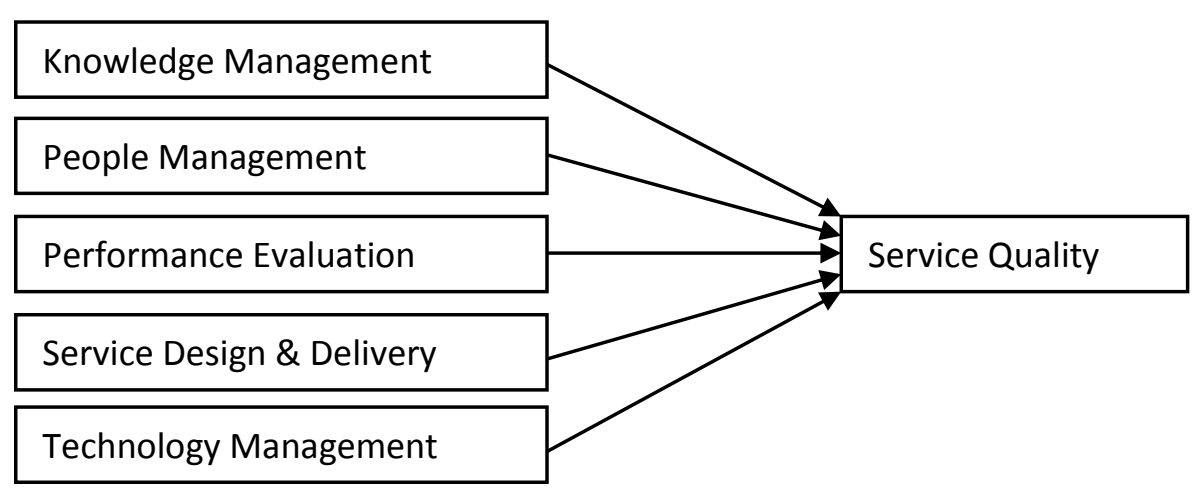

Phase II: the Descriptive Phase: The descriptive phase of the study aimed at providing a quantitative description of the hypothetical model [Figure 1]. This phase was carried out as a quantitative research. A 
structured questionnaire developed using the factors identified during Phase I was used for the primary research carried out in this phase.

Sample: Since the focus of study was high-end ITeS, the population under consideration was service providers of complex and high-end tasks that had been in operation for at least 5 years. The exploratory phase had revealed that front line employees are generally not aware of quality decisions. Therefore, the population under investigation was restricted to senior executives only. Hence, we can argue that the sampling used in the present study was appropriate for the purpose of this study.

The Research Instrument: The literature review and qualitative research had revealed that effective handling of the five determinants reduces service quality gaps. Based on the outcome a questionnaire was designed. The questionnaire consisted of 17 questions. Of these, 16 were designed to collect responses about management of the five factors (Service Design and Delivery, Knowledge Management, Technology Management, People Management and Performance Evaluation) and 1 question for rating the success of the ITeS project. Glynn et al (2003) have posited that reduction in quality gaps results in improved service quality, thereby, resulting in the success of the project. Since a successful project implies good quality, the questionnaire aimed at describing the relationship between the determinants and project success. The choice of an appropriate rating scale for measuring product or service quality is a necessary first step in developing a quality measurement tool. The responses to the questions were taken on a 7-point scale (ranging from 1strongly disagree, to, 7-strongly agree). We used the Likert scale as it provides greater sensitivity of measurement and accommodates various shades of opinion along with a neutral position. The 7-point scale was preferred over a 4- or 5-point scale for its ability to detect smaller differences (Devlin, Dong and Brown, 2003).

Reliability of the Questionnaire: The questionnaire was pre-tested by having several senior ITeS professionals review it to ensure appropriateness in format and wording of questions. The questionnaire was pilot tested with 25 respondents. The scales were tested to assess the reliability of each of the factors included in this study. Internal consistency was evaluated through Cronbach's alpha using SPSS 16.0. Acceptable value of Cronbach's alpha values lie between .70 and .90 (Tavakol and Dennick, 2011). Knowledge Management (3 items, $\alpha=.716$ ) and People Management (4 items, $\alpha=.809$ ) were found to be highly reliable. The Service Design and Delivery scale consisted of 4 items $(\alpha=.681)$. Since the alpha value was close to .7, it was treated as reliable. Cronbach's alphas for the 3 Performance Management items and 4 Technology Management items were .566 and .601 respectively. Low values of alpha can be due to low number of questions (as in the case of Technology Management which had only 2 items) or heterogeneous constructs (as in the case of Performance Evaluation which was evaluated using three items but had low average interitem correlation) (Tavakol and Dennick, 2011) and were therefore treated as acceptable. The reliabilities and inter item co-relation for different constructs are summarized in Table 1 . The overall reliability of the five factors was very high $(\alpha=.876)$ showing high internal consistency. The analysis confirmed the acceptable levels of reliability in all criteria used for the purpose of the present study, especially given the shorter nature of scales.

Table 1: Reliabilities tests

\begin{tabular}{llll}
\hline Variables & $\begin{array}{l}\text { No. of } \\
\text { items }\end{array}$ & $\begin{array}{l}\text { Scale } \\
\text { Reliability } \begin{array}{c}\text { (alpha) } \\
\text { in current study }\end{array}\end{array}$ & $\begin{array}{l}\text { Average inter-item co- } \\
\text { relation in current study }\end{array}$ \\
\hline Knowledge Management & 3 & 0.716 & 0.452 \\
Performance Evaluation & 3 & 0.566 & 0.312 \\
People Management & 4 & 0.809 & 0.526 \\
Service Design and Delivery & 4 & 0.681 & 0.383 \\
Technology Management & 2 & 0.601 & 0.430 \\
\hline
\end{tabular}

Source: Based on data collected from respondents. 
Data Collection: The domain of study was limited to high-end services and choice of respondents was restricted to senior executives of various types of ITeS service provider organizations. Convenience purposive sampling was done. Email invitations were sent to a number of senior executives. In all, 77 questionnaires were distributed and 60 responses were received, giving a response rate of $77.9 \%$. The respondents were requested to select an ITeS project from their experience and record their responses.

\section{Results and Discussion}

The data collected was analyzed using SPSS 16.0. Spearman's Correlation analysis was used to establish the strength of relationship between project success and the five determinants, namely, Knowledge Management, People Management, Performance Evaluation, Service Design and Delivery, and Technology Management. Multiple Regression analysis was used to define how success is explained by the combination of these factors.

Correlation Result Analysis: The output on correlations [Table 2] highlights a significant positive relationship between all five factors and project success and, hence, service quality (Knowledge Management - r=.792, p<.01; People Management - r=.747, p<.01; Performance Evaluation - r=.648, p<0.01, Service Design \& Delivery- $\mathrm{r}=.652, \mathrm{p}<.01$, and Technology Management $-\mathrm{r}=.736, \mathrm{p}<.01$ ). The relationship between project success and knowledge management was found to be the strongest, thereby implying that success of complex high-end ITeS projects depends on effective knowledge management. In addition, a strong positive relationship was found between knowledge management and all the four factors thereby indicating that appropriate knowledge management improves organizational readiness to handle all determinants of service quality.

Table 2: Correlation Analysis Results

\begin{tabular}{|c|c|c|c|c|c|c|}
\hline Variables & Success & $\begin{array}{l}\text { Service Design } \\
\text { \& Delivery }\end{array}$ & $\begin{array}{l}\text { Knowledge } \\
\text { Management }\end{array}$ & $\begin{array}{l}\text { Technology } \\
\text { Management }\end{array}$ & $\begin{array}{l}\text { People } \\
\text { Management }\end{array}$ & $\begin{array}{l}\text { Performance } \\
\text { Evaluation }\end{array}$ \\
\hline Success & 1 & $.652^{* *}$ & $.792^{* *}$ & $.736^{* *}$ & $.747^{* *}$ & $.648^{* *}$ \\
\hline $\begin{array}{l}\text { Service Design } \\
\text { \& Delivery }\end{array}$ & & 1 & $.639^{* *}$ & $.408^{* *}$ & $.573^{* *}$ & $.490^{* *}$ \\
\hline $\begin{array}{l}\text { Knowledge } \\
\text { Management }\end{array}$ & & & 1 & $.667^{* *}$ & $.731^{* *}$ & $.674^{* *}$ \\
\hline $\begin{array}{l}\text { Technology } \\
\text { Management }\end{array}$ & & & & 1 & $.645^{* *}$ & $.480^{* *}$ \\
\hline $\begin{array}{l}\text { People } \\
\text { Management }\end{array}$ & & & & & 1 & $.651^{* *}$ \\
\hline $\begin{array}{l}\text { Performance } \\
\text { Evaluation }\end{array}$ & & & & & & 1 \\
\hline
\end{tabular}

${ }^{* *}$ Correlation is significant at the 0.01 level (2-tailed)

Regression Analysis Results: Multiple regression analysis was used to examine the effects of all five independent variables on the dependent variable i.e. Project Success. The analysis showed that the combined linear effects of, Knowledge Management, People Management, Performance Evaluation, Service Design and Delivery, and Technology Management account for $76.8 \%$ of the variation in project success and hence quality ( $\mathrm{R} 2=.768, \mathrm{~F}(5,59)=35.57, \mathrm{p}<.001$ ) [Table 3]. The relationship between each of the five dependent variables and success was found to be positive and significant. Thus, the success of any ITeS project depends on effective management of the factors. If these factors are managed well, the quality of service will be good and the project will be successful. Technology Management $(\beta=0.330, p=0.001)$ was found to have a very strong relationship with success. Due to the heavy dependence of high-end ITeS on technology, management of issues related to technology has a positive impact on service quality and project success. Service Design and Delivery $(\beta=0.217, p=0.017)$ and Knowledge management $(\beta=0.235, p=0.050)$ were also strong predictors of service quality. The strong relationships indicated that processes for effective service design and capturing and re-using knowledge result in improvement in service quality. People Management $(\beta=$ $0.159, \mathrm{p}=0.151)$ and Performance Evaluation $(\beta=0.122, \mathrm{p}=0.198)$ were found to have a positive but relatively weak relationship with success as compared to the other factors. 
Table 3: Regression Model

\begin{tabular}{lllllll}
\hline \multirow{2}{*}{ Model } & \multicolumn{2}{l}{$\begin{array}{l}\text { Unstandardized } \\
\text { Coefficients }\end{array}$} & $\begin{array}{l}\text { Standardized } \\
\text { Coefficients }\end{array}$ & Sig. & $\begin{array}{l}\text { Dependent } \\
\text { Success }\end{array}$ & Variable: \\
\cline { 2 - 6 } & B & Std. Error & Beta & & & \\
\hline (Constant) & -.429 & .480 & & 0.376 & R Square & .768 \\
Service Design \& Delivery & .224 & .090 & .217 & 0.017 & Adjusted R Square & .746 \\
Knowledge Management & .242 & .123 & .235 & 0.050 & F change & 35.57 \\
Technology Management & .278 & .078 & .330 & 0.001 & Sig. F Change & .000 \\
People Management & .139 & .095 & .159 & 0.151 & & \\
Performance Evaluation & .143 & .109 & .122 & 0.198 & & \\
\hline
\end{tabular}

Discussion: The study investigated the factors that affect quality of service particularly in context of high-end ITeS such as engineering design, business transformation services, knowledge process outsourcing and financial analysis. The findings on the strong relationship between ITeS project success and Technology Management were in line with Sureshchandar et al (2002), Ganguli, and Roy (2010). As high-end ITeS service and its delivery both are heavily dependent on technology, quality depends on effective technology management. The findings of the regression analysis showed a significant and positive relationship between Service Design \& Delivery and Success, as proposed by Sureshchandar et al (2002) and Duraivelu and Suryaprakasa (2006). Clearly, mechanisms that ensure effective capturing of customers' requirements, and designing and delivering services as per the requirements are essential to service quality. The ability of the service provider to understand what the client requires (Hyder et al, 2004; Ren and Zhou, 2008) therefore becomes a critical determinant of service quality. A strong, positive and significant correlation was found between project success and Knowledge Management. This was in line with Yoon and Suh (2004), as in complex service scenarios the ability of organizations to capture and re-use task related knowledge is a critical determinant. The dissemination of appropriate knowledge can reduce re-work, thus contributing to improved quality. The correlations between success and People Management and Performance Management, both, were positive; however, both relationships were not very significant. These findings were surprising as Blanchard and Galloway (1994), Mukherjee and Malhotra (2006), Ganguli and Roy (2010) had posited that strong relationship exists between People Management and service quality. Similarly, studies by Jiang et al (2002), Rottman, and Lacity (2006) have proposed that Performance Evaluation has a positive relationship with service quality. However, in the context of our study these relationships were not found to be significant. Having appropriate quality metrics, continuous monitoring and benchmarking of service metrics is important for overall control, but does have a direct significant relationship with service quality. An important finding of the study was the role of Knowledge Management. Apart from having a positive effect on service, quality, strong and significant correlations were found between Knowledge Management and the other four factors. This further highlights the role of Knowledge Management in complex service domains. The correlations show that Knowledge Management spans the entire service lifecycle and has the potential to mitigate all gaps by capturing, retaining and disseminating learning from experiences. Hence, we can conclude that in order to counter the antecedents to service quality gaps, organizations require processes, which can contribute to organizational learning as proposed by Yoon and Suh (2004). The hypothetical model can, therefore, be modified as shown in Figure 2.

\section{Implications for Managers}

This study provides implications and offers suggestions for Indian service providers providing high-end services. The determinants identified provide a starting point for quality management in this context. The strong relation between Knowledge Management and all other determinants indicate a potential area of effective quality management that can be leveraged by service providers. While the commonly used quality frameworks in the Indian ITeS are comprehensive and elaborate, none of them emphasize on the role of Knowledge Management. This becomes even more relevant in context of complex tasks where the nature of tasks makes it difficult to get them right in one go. This results in re-work leading to cost and time over-runs. In traditional quality parlance, both cost and time overruns are indicators of poor service quality. Hence, 
mechanisms of knowledge management to retain in-project and between-project learning have the potential to reduce re-work and improve quality. This provides a fresh perspective of service quality. The implications of this study include the idea that to become a leader in the competitive market, apart from quality frameworks, which handle other critical determinants, introduction of mechanisms of capturing and reusing organizational knowledge, should be a key thrust area to have a competitive advantage.

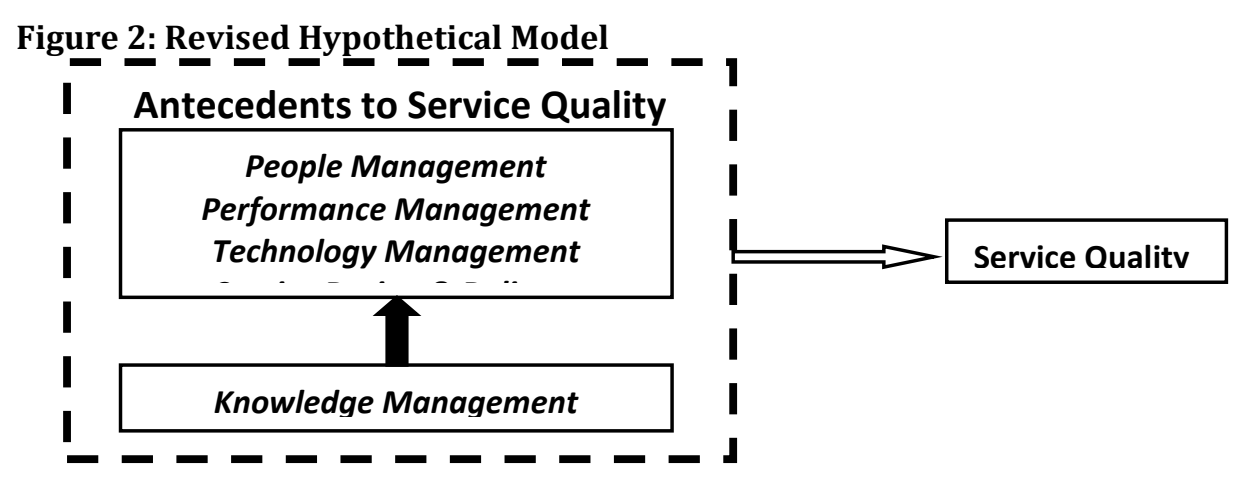

Research Implications and Limitations: This paper will allow for better understanding of the factors that affect service quality in the given context. The study has not been able to completely define the role of People Management and Performance Evaluation. In addition, the inter-relationships between the factors need further investigation. Confirmatory factor analysis using Structural Equation Modelling could not be performed on the data, which could have helped to measure the fit indices. Clearly, the next step is to empirically test the inter-relationships between these constructs in order to generate appropriate value propositions. The revised hypothetical model also needs further investigation. With the changing ITeS service scenario and emergence of China and Philippines as outsourcing destination, the pressure on Indian ITeS service providers has intensified. For India to maintain its status of global ITeS hub in all services, traditional as well as high-end, organization wide strategies and processes are required to ensure service quality. The road map for service quality management presented in this paper will clearly pave way for better understanding of service quality in the emerging domain of complex and high-end IT-enabled Services.

\section{References}

Alzola, L. C. \& Robaina, V. P. (2005). SERVQUAL and its applicability in Electronic Commerce B2C. The Quality Management Journal, 12(4), 46-57.

Aron, R., Bandyopadhyay, S., Jayanty, S. \& Pathak, P. (2008). Monitoring process quality in offshore outsourcing: A model and findings from multi-country survey. Journal of Operations Management, 26(2), 303-321.

Beaumont, N. \& Costa, C. (2002). Information Technology outsourcing in Australia. Information Resources Management Journal, 15(3), 14-31.

Blanchard, R. F. \& Galloway, R. L. (1994). Quality in Retail Banking. International Journal of Service Industry Management, 5(4), 5-23.

CRISIL Report (2011). http://www.crisil.com/pdf/research/research-industry-information-report-itenabled-services-ites-contents.pdf, accessed on 25 June 2011.

Devlin, S. J., Dong, H. K. \& Brown, M. (2003). Selecting a Scale for Measuring Quality. Marketing Research, $5(3), 13-18$.

Duraivelu, K. \& Suryaprakasa Rao, K. (2006). ProducQual- A conceptual model for quality gap analysis across PLC. Journal of Indian Institute of Science, 86(2), 113-124.

Ganguli, S. \& Roy, S. K. (2010). Service quality dimensions of hybrid services. Managing Service Quality, 20(5), 404-424.

Glynn, W. J., de Burca, S., Brannick T., Fynes, B. \& Ennis, S. (2003). Listening Practices and Performance in Service Organizations. International Journal of Service Industry Management, 14(3), 310-330.

Harmon, E. P., Hensel, S. C. \& Lukes, T. E. (2006). Measuring Performance in Services. The McKinsey Quarterly, 14(1), 31-39. 
Hsieh, Y. H., Lin, C. J. \& Chen, J. C. (2007). Customer Satisfaction measurement with Neural network. Human Systems Management, 26(1), 47-52.

http://www.indiaprline.com/2011/02/17/cii-pwc-report-on-changing-landscape-and-emerging-trendsindian-itites-industry-released-about-the-report/ Accessed on 20.6.2011

Hyder, E. B., Heston, K. M. \& Paulk, M. C. (2004). The eSourcing capability model for service providers, version 2 - model overview, Part 1 and Part 2 (Technical Report No. CMU-ISRI-04-113 and CU-ISRI-04-114). Pittsburgh, PA: Carnegie Mellon University, Institute for Software Research International.

Jiang, J. J., Klein G. \& Carr, C. I. (2002). Measuring Information System Service Quality: SERVQUAL from the other side. MIS Quarterly, 26(2), 145-166.

Lacity, M. C. \& Willcocks, L. P. (1998). An Empirical Investigation of Information Technology Sourcing Practices: Lessons from Experience. MIS Quarterly, 22(3), 363-408.

Mukherjee, A. \& Malhotra, N. (2006). Does Role Clarity explain Employee-perceived Service Quality? A study of Antecedents and Consequences in Call Centres. International Journal of Service Industry Management, 17(5), 444-473.

NASSCOM and Booze \& Co. (2010). Report on Global ER\&D, Accelerating Innovation with Indian Engineering, accessed on 5 September 2011, available at http://www.booz.com/media/uploads/NASSCOM_Booz_ESR_Report_2010.pdf

Parasuraman, A., Zeithaml, V. A. \& Berry, L. L. (1985). A Conceptual Model of Service Quality and Its Implications for Future Research. Journal of Marketing, 49(3), 41-50.

Parasuraman, A. (2005). E-S-QUAL: A Multiple-Item Scale for Assessing Electronic Service Quality. Journal of Service Research, 7(3), 213-233.

Ramachandran, K. \& Voleti, S. (2004). Business process outsourcing (BPO): emerging scenario and strategic options for IT-enabled services. Vikalpa, 29(1), 49-62.

Ramani, S. (2000). IT Enabled Services: Growing Form of Telework. Economic and Political Weekly, 35(26), 2305-2307.

Ren, Z. J. \& Zhou, Y. P. (2008). Call Center Outsourcing: Coordinating Staffing Level and Service quality. Management Science, 54(2), 369-383.

Ronnback, A., Witell, L. \& Enquist, B. (2009). Quality management systems and Value Creation. International Journal of Quality and Service Sciences, 1(3), 241-254.

Rottman, J. W. \& Lacity, M. C. (2006). Proven Practices for Effectively Off shoring IT Work. MIT Sloan Management Review, 47(3), 56-63.

Scandura, T. A. \& Williams, E. A. (2000). Research Methodology in Management: Current Practices, Trends, and Implications for Future Research. Academy of Management Journal, 43(6), 1248-1264.

Sohn, C. \& Tadisina, S. K. (2008). Development of e-service quality measure for internet-based financial institutions. Total Quality Management, 19(9), 903-918.

Sureshchandar, G. S., Rajendran, C. \& Anantharaman, R. N. (2002). Determinants of customer perceived service quality: A confirmatory factor analysis approach. Journal of Services Marketing, 16(1), 9-34.

Susarla, A., Barua, A. \& Whinston, A. B. (2003). Understanding the Service Component of Application Service Provision: An Empirical Analysis of Satisfaction with ASP Services. MIS Quarterly, 27(1), 91-123.

Thelen, S. T., Zarb, F. G., Honeycutt-Jr., E. D. \& Murphy, T. P. (2010). Services off shoring: Does perceive service quality affects country-of-service origin preference? Managing Service Quality, 20(3), 196-212.

Tavakol, M. \& Dennick, R. (2011). Making sense of Cronbach's alpha. International Journal of Medical Education, 2, 53-55.

Willcocks, L., Hindle, J., Feeny, D. \& Lacity, M. (2004).IT and Business Process Outsourcing: The Knowledge Potential. Information Management, 21(3), 7-15.

Yoon, S. \& Suh, H. (2004). Ensuring IT Consulting SERVQUAL and User Satisfaction: A Modified Measurement Tool. Information Systems Frontier, 6(4), 341-351.

Zeithaml, V. A., Parasuraman. A. \& Berry, L. L. (1990). Delivering Quality Service - Balancing Customer Perceptions and Expectations, New York: The Free Press, Macmillan Inc.

Zeithaml, V. A., Parasuraman, A. \& Malhotra, A. (2002). Service Quality Delivery through Web Sites: A Critical Review of Extant Knowledge. Journal of the Academy of Marketing Science, 30(4), 362-375. 